\title{
The Stimulatory Effect of Cholecystokinin Implanted in the Medial Preoptic Area on Luteinizing Hormone Secretion in the Ovariectomized Estrogen-Primed Rat
}

\author{
Fukuko KIMURA,* Ryuhei HASHIMOTO And MASAZumi KAWAKAMI \\ Department of Physiology, Yokohama City University School of Medicine, \\ 2-33 Urafune-cho, Minami-ku, Yokohama 232
}

\begin{abstract}
The effect of implantation of cholecystokinin(CCK)-8 into the medial preoptic area (MPO) through the chronically implanted guide cannula on the release of LH was examined in the ovariectomized estradial-primed rat. An inner cannula with CCK-8 at the tip, as well as an empty inner cannula as the control, was implanted into the MPO at $12.00 \mathrm{~h}$. Blood samples were obtained at $11.00,12.00,16.00,18.00$ and $20.00 \mathrm{~h}$, and serum concentration of $\mathrm{LH}$ was measured by RIA. There was no significant fluctuation over time in the mean serum LH values for each sampling time in the group of animals implanted with empty cannulae in the MPO. In the group of animals implanted with CCK-8 into the MPO, the fluctuation of the mean LH values over time was significant, with a marked and significant elevation of LH values peaking at $16.00 \mathrm{~h}$.

It was strongly suggested that CCK-8 was capable of stimulating LH-RH release, acting at the MPO.
\end{abstract}

Since the discovery of a gastrointestinal hormone, cholecystokinin (CCK) in the brain, many studies have been directed at finding the functional significance of this peptide in the brain (Dockray, 1976, Muller et al., 1977). Concerning the influence on the secretion of anterior pituitary hormones, it has been reported that an intraventricular injection of CCK-8 in the ovariectomized rat produced a decline of plasma luteinizing hormone $(\mathrm{LH})$ but elevated prolactin levels (Vijayan et al., 1979). In the same study, plasma growth hormone levels rose but TSH levels fell. It was further reported that an intraventricular injection of CCK-8 induced an elevation of plasma

\footnotetext{
Received March 26, 1983

* To whom reprint requests should be addressed.

This article is dedicated to the memory of Professor M. Kawakami, under whom we had the preasure of studying and working.
}

corticosterone levels (Itoh et al., 1979, Fekete et al., 1981).

On the basis of these findings, we have attempted to obtain more strict evidence supporting the role of CCK in the control of $\mathrm{LH}$ secretion by observing the effect of CCK implants into a localized area of the brain.

\section{Materials and Methods}

Female Wistar rats weighing 250-300 g maintained in a light-controlled (lights on from 05.00 to $19.00 \mathrm{~h}$ ) room had been ovariectomized and implanted with guide cannulae in the medial preoptic area (MPO) 3 weeks later. The cannulae were made of $0.75 \mathrm{~mm}$ outer diameter stainless steel tube and were stereotaxically implanted unilaterally according to the atlas by Albe-Fessard et al. (1966) under anesthesia with pentobarbital sodium. They were fixed to the skull using dental cement. Two weeks after the implantation of the guide cannula, the animal was primed 
with $20 \mu \mathrm{g}$ of estradiol benzoate in sesame oil at $12.00 \mathrm{~h}$. At $12.00 \mathrm{~h}$ on the third day after the estrogen priming, powder CCK-8 (sulfated form, Squibb Co.), which was kindly donated by Dr. F. Kobayasi (Shionogi Research Laboratories, Shionogi Co.), was implanted through the inner cannula which was made of $0.30 \mathrm{~mm}$ outer diameter stainless steel tube. The inner cannulae containing CCK-8 at their tips were prepared by gently tamping the tubes into a watch glass containing the CCK-8. Material on the outer surface of the tubing was carefully removed, and then cannula was inserted through the guide cannula into the MPO without anesthesia. The control animals were implanted with empty cannulae.

$0.5 \mathrm{ml}$ blood samples were taken through an intraatrial cannula of silastic tube placed under anesthesia with ether on the day before the experiment, and an equal volume of heparinized $(10 \mathrm{U} / \mathrm{ml}) \quad 0.9 \%$ saline was replaced. Samplings were done at 11.00 , 12.00 just before the CCK-8 implantation, 16.00 , 18.00 and $20.00 \mathrm{~h}$. After the final bleeding at $20.00 \mathrm{~h}$, the rat was anesthetized with pentobarbital sodium and perfused with $10 \%$ buffered formalin. The sites of implantation were microscopically identified in frontal sections of the brains.
Serum LH concentrations were measured with a radioimmunoassay kit supplied by the NIAMDD. The method was principally based on the double antibody procedure described in the instructions with the kit. The referential standard was NIAMDD rat LH RP-1, and the LH values are expressed in terms of NIH-LH-S1. The mean minimally detectable amount of LH $(95 \%$ confidence limits of buffer controls) on 3 assays was $0.23 \pm 0.12$ (SD) $\mathrm{ng} / \mathrm{ml}$. The within- and between-assay variance for the 3 assays, which were calculated from the triplicate determinations in each assay for the pool of rat serum containing $2.62 \pm 0.12(\mathrm{SE}) \mathrm{ng} / \mathrm{ml}(\mathrm{n}=9)$, were $2.1 \%$ and $12.4 \%$, respectively.

Two way analysis of variance and the multiple range test of Duncan were used to test the statistical significance of fluctuations over time in the mean $\mathrm{LH}$ values for each sampling time. Student's $t$-test was used to test the significance of difference between groups of animals implanted with inner cannulae with and without CCK-8 at a particular time.

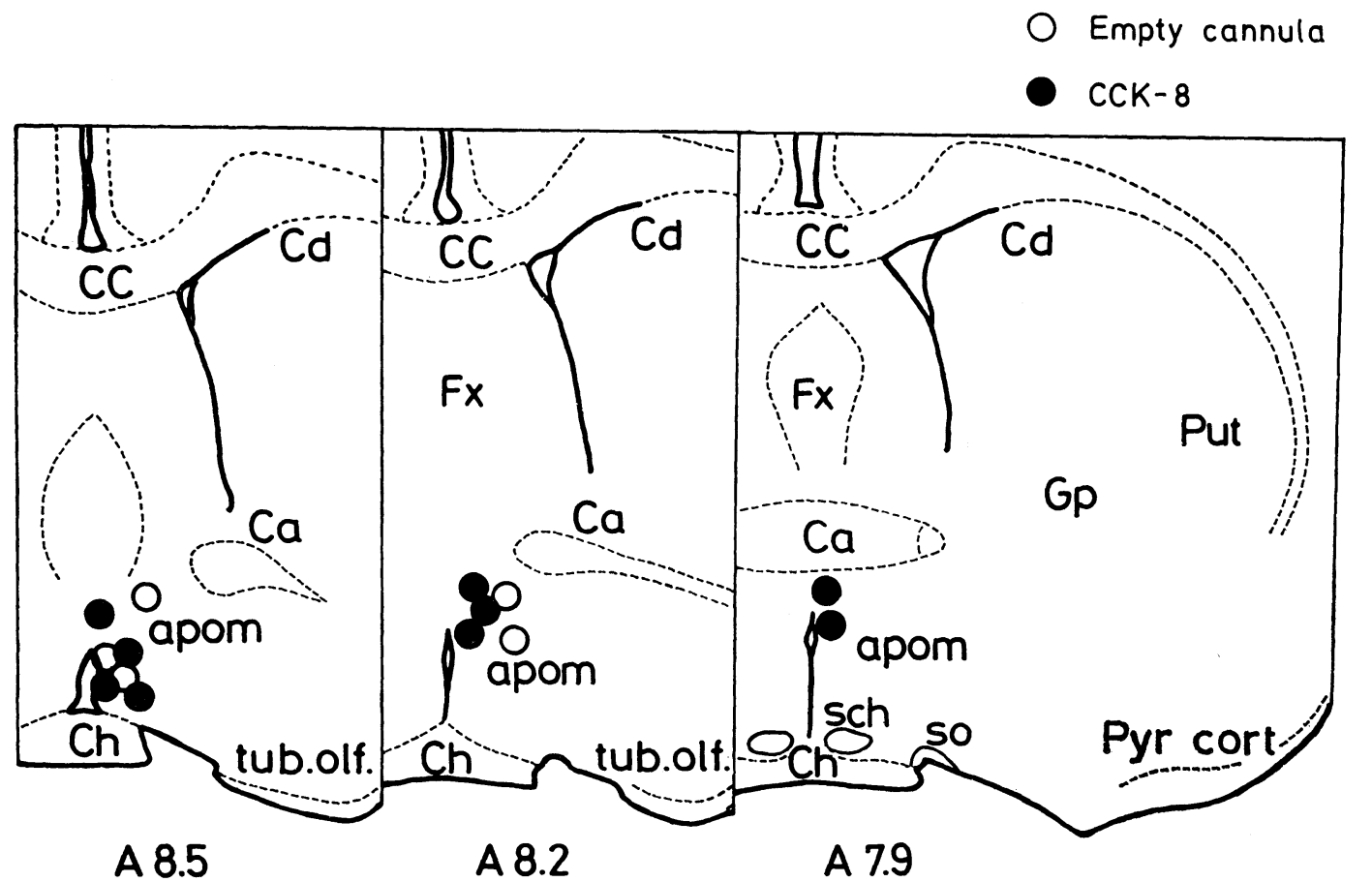

Fig. 1. Diagram summarizing the sites of CCK-8 implantations. The areas of cannula tips with CCK8 , as well as those of empty cannula tips are shown on frontal sections modified from the atlas of Albe-Fessard et al. (1966). Abbreviations ; apom: area preoptica medialis, Ca : Commissura anterior, CC: Corpus callosum, Cd: nucleus Caudatus, Ch: Chiasma opticum, Fx: Fornix, Gp: Globus pallidus, Put: Putamen, Sch: nucleus suprachiasmaticus, and so: nucleus supraoptics. 


\section{Results}

The sites of the implantation of CCK-8, as well as of the implantation of empty cannula in the MPO are shown in Fig. 1. The mean $( \pm \mathrm{SE})$ values of serum concentration of $\mathrm{LH}$ for each sampling time are shown diagramatically in Fig. 2.

In the group of animals in which empty cannulae were implanted in the MPO, the fluctuation of mean $\mathrm{LH}$ values over time was shown to be not significant by analysis of variance. In contrast, in the animals which were implanted with CCK-8 in the MPO, there was observed a marked eleva- tion of serum LH levels 4-6 h afterwards. Analysis of variance revealed that the fluctuation of mean LH values over time was significant $(\mathrm{p}<0.01)$, and mutiple range test revealed that the levels at 16.00 and $18.00 \mathrm{~h}$ were significantly higher than those preimplanted $(p<0.01)$. Since the level at $18.00 \mathrm{~h}$ was quite low compared with the level at $16.00 \mathrm{~h}(\mathrm{p}<0.01)$, it seemed that the elevation of $\mathrm{LH}$ had attained its maximum by $16.00 \mathrm{~h}$. Further, as apparent in Fig. 2, differences in $\mathrm{LH}$ levels between the groups of empty cannulae and CCK-8 were significant at $16.00 \mathrm{~h}(\mathrm{p}<0.001)$ and $18.00 \mathrm{~h}(\mathrm{p}<0.05)$.

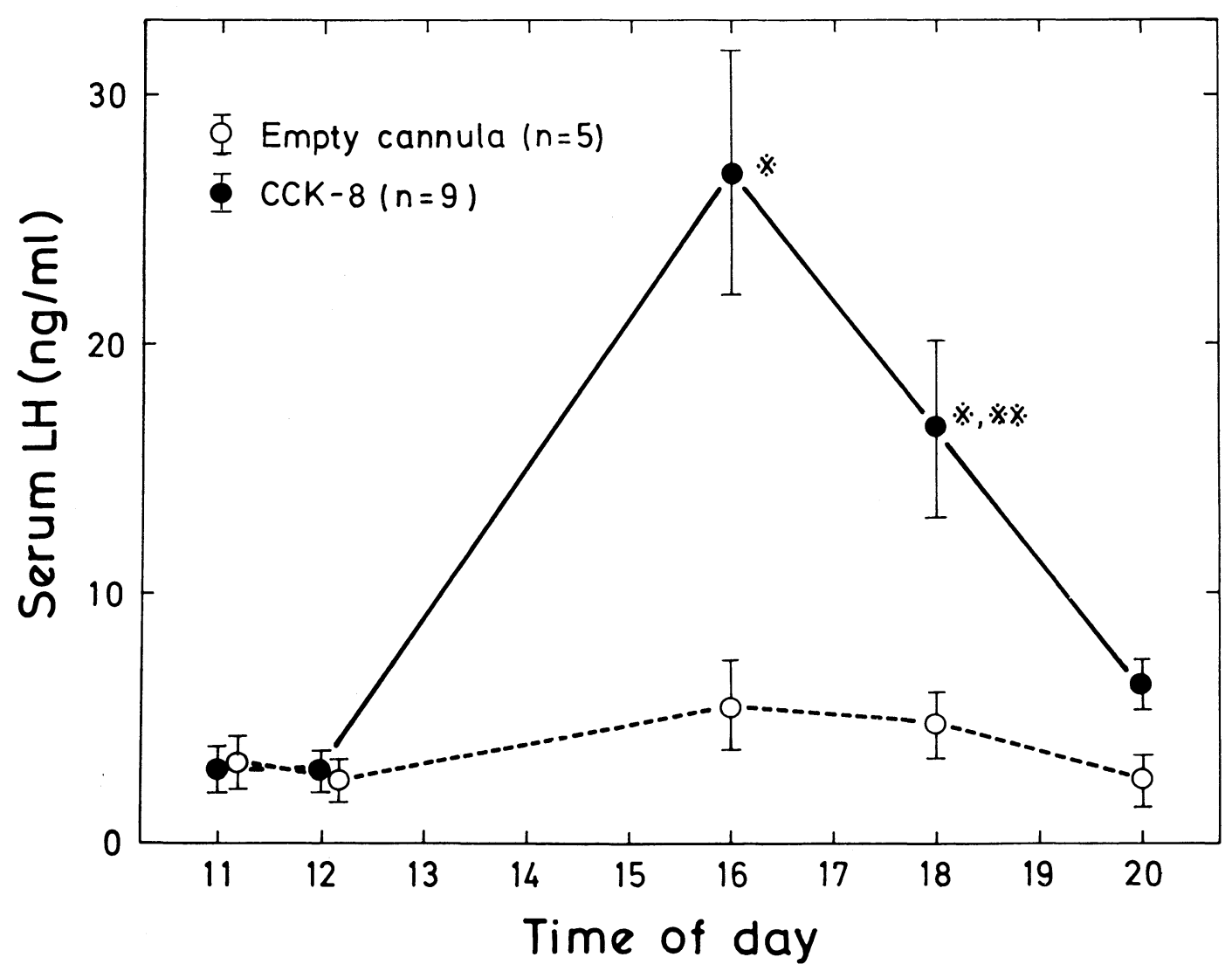

Fig. 2. Effect of CCK-8 implantation in the MPO on serum LH levels of ovariectomized estradiolprimed rat. Each point represents the mean and the vertical lines indicate the SE. Numbers in parentheses show number of animals in each group.

$* \mathrm{p}<0.01$ vs levels at 11.00 and $12.00 \mathrm{~h}$. ** $\mathrm{p}<0.01$ vs levels at $16.00 \mathrm{~h}$. 


\section{Discussion}

The results of the present experiment show clearly that CCK- 8 implanted in the MPO is capable of stimulating the release of LH-RH, and subsequently the release of LH. Certainly, this was unexpected and surprising, since Vijayan et al. (1979) have shown that either the third ventricular or the intravenous administration of $\mathrm{CCK}-8$ produced a rapid and significant supression of plasma LH levels which continued for at least $1 \mathrm{~h}$.

However, this discrepancy in the CCK effects between the ventricular administration and the MPO implantation reminded us of a paradoxical effect of dopamine (DA) we had found previously. That is, DA implants in the MPO in the ovariectomized estradiol-primed rat did induce a significant release of LH (Kawakami et al., 1975, 1979), despite controversy over the role of DA in the stimulation of $\mathrm{LH}$ release. It had been reported that DA was effective in stimulating LH release (Schneider and McCann, 1970), whereas an inhibitory effect was indicated by other studies (Fuxe et al., 1975, Gnodde and Schuiling, 1976). We had also found that an intravenous injection of DA lowered serum LH levels in the proestrous rat (Kimura et al., 1975). However, the finding that DA was effective in stimulating $\mathrm{LH}$ release when implanted in a localized area, the MPO, seemed to account for the discrepancy between the results of many studies concerning the role of $\mathrm{DA}$; we assumed that DA would act at the dual levels, at the MPO and the median eminence, inducing opposite effects on LH release (Kawakami et al., 1975, 1979.)

The present finding that implantation of CCK- 8 in the MPO stimulated LH release and the finding by Vijayan et al. (1979) that intraventricular administration supressed it appeared to be in the same relationship as the findings for DA. Namely, it is very probable that $\mathrm{CCK}-8$ administered intravenously may act at the median eminence and inhibit LH-RH release, whereas CCK- 8 implanted in the MPO may act at that level and stimulate LH-RH release. It has been reported that all nuclei of the rat hypothalamus including anterior preoptic nuclei contained moderate concentrations of CCK-8, although there was a considerable gradient of concentration in the hypothalamus with the median eminence, ventromedial and arcuate nuclei being the highest (Beinfeld et al., 1981, Vanderhaeghen et al., 1980, Anhut et al., 1983). In the guinea pig, CCK neurons were particularly numerous in the MPO (Larsson and Rehfeld, 1979). In addition, it has been shown that CCK receptors were present in the brain areas where CCK distributed (Saito et al., 1980). Those chemical findings would support our concept of the dual regulation of CCK-8 concerning $\mathrm{LH}$ release; i.e., at the MPO and the median eminence.

In relation with the very similar effects on LH release exerted by the CCK- 8 and DA, recent studies have produced the interesting finding that some mesencephalic DA neurons projecting mainly to the limbic areas contained a CCK-8-like peptide (Hökfelt et al., 1980). Although no evidence has been obtained that other DA neuron systems, such as the incerto-hypothalamic DA system which has been shown to send an abundance of fibers to the preoptic anterior hypothalamus (Björklund et al., 1975), had CCK, it is possible that CCK and DA, which are contained in the same neuron, act synergistically, or at least, interact with each other, in carrying out their physiological functions. In support of this theory, Hökfelt et al. (1980) also demonstrated that CCK administered intraventricularly reduced DA turnover in some of the mesolimbic DA neurons that have been shown to contain CCK-8-like peptide. This speculation appears very atractive and thus our nett subject is to obtain the evidence. 


\section{Acknowledgements}

We wish to thank the National Institute of Arthritis, Metabolism and Digestive Diseases for supplying radioimmunoassay materials. The authors also thank Dr. K. Wakabayashi, Institute of Endocrinology, Gunma University for his kind help with the measurement of LH. The present work was supported by a Grant-in-Aid for Scientific Research from the Ministry of Education, Science and Culture of Japan.

\section{References}

Albe-Fessard, D., Stutinsky, F., Libouban, S. (1966). Atals stéréotaxique du diencéphale du rat blanc, Editions du Centre National de la Recherche Scientifique, Paris.

Anhut, H., K. Dieter and W. Knepel (1983).I Cholecystokinin-like immunoreactivity of rat medial basal hypothalamus: Investigations on a possible hypophysiotropic function. Neuroendocrinology 36, 119-124.

Beinfeld, M. Y., D. K. Meyer, R. L. Eskay, R. T. Jensen and M. J. Brownstein (1981). The distribution of cholecystokinin immunoreactivity in the central nervous system of the rat as determined by radioimmunoassay. Brain Res. 212, 51-57.

Björklund, A., O. Lindvall and A. Nobin (1975). Evidence of an incerto-hypothalamic dopamine neurone system in the rat. Brain Res. 89, 146159.

Dockray, G. J. (1976). Immunochemical evidence of cholecystokinin-like peptides in brain. Nature 264, 568-570.

Fekete, M., M. Bokor, B. Penke, K. Kovács and G. Telegdy (1981). Effects of cholecystokinin octapeptide and its fragments on brain monoamines and plasma corticosterone. Neurochem. Int. 3, 165-169.

Fuxe, K., K. Andersson, V. Locatelli, L. F. Agnati, T. Hökfelt, L. Skirboll and V. Mutt (1980). Cholecystokinin peptides produce marked reduction of dopamine turnover in discrete areas in the rat brain following intraventricular injection. Europ. J. Pharmacol. 67, 329-331.

Fuxe, K., T. Hökfelt, A. Löfström, O. Johansson, L. Agnati, B. Everitt, M. Goldstein, S. Jeffcoate, N. White, P. Eneroth, J.-A. Gustafsson and P. Skett. (1976). On the role of neurotransmitters and hypothalamic hormones and their interactions in hypothalamic and extrahypothalamic control of pituitary function and sexual behavior. In : Sub- cellular Mechanisms in Reproductive Neuroendocrinology (F. Naftolin, K. J. Ryan and J. Davies, eds.), Elsevier Scientific Publishing Co., Amsterdam pp. 193-246.

Gnodde, H. P. and G. A. Schuiling (1976). Involvement of catecholaminergic and cholinergic mechanisms in the pulsatile release of $\mathrm{LH}$ in the long term ovariectomized rat. Neuroendocrinology 20, 212-223.

Hökfelt, T., L. Skirboll, J. F. Rehfeld, M. Goldstein, K. Markey and O. Dann (1980). A subpopulation of mesencephalic dopamine neurons projecting to limbic areas contains a cholecystokinin-like peptide; Evidence from immunohistochemistry combined with retrograde tracing. Neuroscience 5, 2093-2124.

Itoh, S., R. Hirota, G. Katsuura and K. Odaguchi (1979). Adrenocortical stimulation by a cholecystokinin preparation in the rat. Life Sci. 25, 1725-1730.

Kawakami, M., J. Arita, F. Kimura and R. Hayashi (1979). The stimulatory roles of catecholamines and acetylcholine in the regulation of gonadotropin release in ovariectomized estrogen-primed rats. Endocrinol. Japon. 26, 275-284.

Kawakami, M., F. Kimura, M. Manaka and S. Kawagoe (1975). LH discharge induced by medial preoptic implantation of estrone or dopamine in the ovariectomized estradiol primed rat. Endocrinol. Japon. 22, 549-554.

Kimura, F., S. Sakuma and M. Kawakami (1975). Monoaminergic control of gonadotropin release. Nihon Rinsho 33, 534-538 (In Japanese).

Larsson, L.-I. and J. F. Rehfeld (1979). Localization and molecular heterogenity of cholecystokinin in the central and peripheral nervous system. Brain Res. 165, 201-218.

Muller, J. E., E. Straus and R. S. Yalow (1977). Cholecystokinin and its $\mathrm{COOH}$-terminal octapeptide in the pig brain. Proc. Natl. Acad.Sci. U.S.A. 74, 3035-3037.

Saito, A., H. Sankaran, I. D. Goldfine and J. A. Williams (1980). Cholecystokinin receptors in the brain: Characterization and distribution. Science 208, 1155-1156.

Schneider, H. P. G. and S. M. McCann (1970). Mono- and indolamines and control of LH-secretion. Endocrinology 86, 1127-1133.

Vanderhaeghen, J. J., F. Lostra, J. De Mey and C. Gilles (1980). Immunohistochemical localization of cholecystokinin- and gastrin-like peptides in the brain and hypophysis of the rat. Proc. Natl. Acad. Sci. U.S.A. 77, 1190-1194.

Vijayan, E., W. K. Samson and S. M. McCann (1979). In vivo and in vitro effects of cholecystokinin on gonadotropin, prolactin, growth hormone and thyrotropin release in the rat. Brain Res. 172, 295-302. 